\title{
Intrapericardial denervation: responses to water immersion in rhesus monkeys

\author{
NASA-TM-113036
}

\author{
KENNETH H. MCKEEVER, LANNY C. KEIL, AND HAROLD SANDLER \\ College of Veterinary Medicine, The Ohio State University, Columbus, Ohio 43210; \\ and Cardiovascular Research Laboratory, National Aeronautics and Space \\ Administration-Ames Research Center, Moffett Field, California 94035
}

\begin{abstract}
McKeever, Kenneth H., Lanny C. Keil, and Harold Sandler. Intrapericardial denervation: responses to water immersion in rhesus monkeys. Am. J. Physiol. 268 (Regulatory Integrative Comp. Physiol. 37): R1040-R1049, 1995.Eleven anesthetized rhesus monkeys were used to study cardiovascular, renal, and endocrine alterations associated with $120 \mathrm{~min}$ of head-out water immersion. Five animals underwent complete intrapericardial denervation using the Randall technique, while the remaining six monkeys served as intact controls. Each animal was chronically instrumented with an electromagnetic flow probe on the ascending aorta, a strain gauge pressure transducer implanted in the apex of the left ventricle (LV), and electrocardiogram leads anchored to the chest wall and LV. During immersion, LV end-diastolic pressure, urine flow, glomerular filtration rate, sodium excretion, and circulating atrial natriuretic peptide (ANP) each increased $(P<0.05)$ for intact and denervated monkeys. There were no alterations in free water clearance in either group during immersion, yet fractional excretion of free water increased $(P<0.05)$ in the intact monkeys. Plasma renin activity (PRA) decreased $(P<0.05)$ during immersion in intact monkeys but not the denervated animals. Plasma vasopressin (PVP) concentration decreased $(P<0.05)$ during the first 30 min of immersion in both groups but was not distinguishable from control by $60 \mathrm{~min}$ of immersion in denervated monkeys. These data demonstrate that complete cardiac denervation does not block the rise in plasma ANP or prevent the natriuresis associated with head-out water immersion. The suppression of PVP during the first minutes of immersion after complete cardiac denervation suggests that extracardiac sensing mechanisms associated with the induced fluid shifts may be responsible for the findings.
\end{abstract}

water immersion; natriuresis; vasopressin; cardiac denervation; monkey

DURING WATER IMMERSION the induced external hydrostatic pressure forces blood and body fluids toward the heart and head, causing a significant rise in atrial pressure and pronounced neural and hormonal responses $(1,13,14,23,26,27,36)$. Resulting stimulation of low-pressure baroreceptors, the so-called GauerHenry reflex, appears to cause inhibition of vasopressin via vagal pathways to the hypothalamus $(13,14)$. The hemodynamic response to the resulting headward fluid shift is a change in vascular tone and venous resistance and a redistribution of blood flow from arterial to venous sides of the circulation and a final return of atrial pressure to normal levels. Decreases in circulating vasopressin cause a reduction in sensed increased central vascular fluid volume through an increase in urine flow and a free water diuresis $(12,16,18,21,22,33)$.

In contrast to consistent findings in the dog (14), Gilmore and co-workers $(17,18)$ found that volume expansion and water immersion-induced diuresis and natriuresis in nonhuman primates are not attenuated by vagotomy and/or sectioning of dorsal root ganglia. Urine flow and salt loss were also unaffected by cardiac denervation after volume loading in this latter animal model (16, 37). Similarly, Myers et al. (32) reported that a diuresis and natriuresis occurred after water immersion-induced central volume shifts in human cardiac transplant patients. These findings indicate that observed responses may occur by mechanisms other than loss of vagal afferent traffic and/or input from lowpressure baroreceptors, as postulated by Gauer and colleagues $(13,14)$.

To further study this phenomenon, the cardiovascular, endocrine, and renal responses to head-out water immersion in intact rhesus monkeys were compared with the identical responses of monkeys that had undergone complete intrapericardial denervation. Maintenance of a water immersion response in a denervated model would confirm previous reported studies using fluid loading in this model (37) and point to possible mechanisms for the observed findings.

\section{MATERLALS AND METHODS}

Eleven mature and healthy rhesus monkeys, weighing between 4.5 and $10.2 \mathrm{~kg}$, were used in conformance with the "Guiding Principles in the Care and Use of Animals" of the American Physiological Society. All 11 animals were adapted to their housing several months before the experiment.

Five animals ( 2 males and 3 females) underwent complete intrapericardial denervation by use of the Randall technique (38). This procedure produces efferent and afferent cardiac denervation through intrapericardial sectioning of sympathetic and parasympathetic nerves. Included were sectioning of the intrapericardial branches of the left and right thoracic vagi and ventrolateral cardiac nerve, as well as the nervous tissue surrounding the base of the heart (the aorta and pulmonary artery), atria, and the vena cava. The procedure sections the vagal paths to the heart but does not interrupt pathways to other organs. The procedure completely denervates the cardiac receptors, but it spares the high-pressure sinoaortic baroreceptor pathways. During this procedure, the left and right thoracic vagi and the left and right stellate ganglia were identified and stimulated using a Grass stimulator (Grass Instruments, Quincy, MA) and bipolar leads (38). Completeness of efferent cardiac denervation was verified by a lack of heart rate response to vagal and stellate ganglia stimulation. Additionally, after surgery and over the course of subsequent procedures, the completeness of efferent denervation was verified by pharmacological challenge with a continuous intravenous infusion of phenylephrine $\left(2 \mathrm{mg} \cdot \mathrm{kg}^{-1} \cdot \mathrm{min}^{-1}\right.$, $\left.2 \mathrm{~min} ; 4 \mathrm{mg} \cdot \mathrm{kg}^{-1} \cdot \mathrm{min}^{-1}, 2 \mathrm{~min} ; 8 \mathrm{mg} \cdot \mathrm{kg}^{-1} \cdot \mathrm{min}^{-1}, 2 \mathrm{~min}\right)$ and bolus injection of $0.95 \mathrm{mg}$ of atropine $5 \mathrm{~min}$ after cessation of the phenylephrine infusion. Lack of heart rate change from 


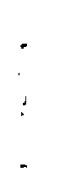


resting levels was considered an indication of completeness of efferent denervation. Finally, we previously reported (31) that there are no changes in radial artery blood flow (RABF) or heart rate (HR) in cardiac-denervated animals during a ramp of lower body negative pressure (LBNP). RABF and HR responses were measured in all monkeys during a ramp of LBNP that was performed within 3 days after the water immersion trials. RABF decreased and HR increased in intact animals during LBNP, whereas there were no changes in RABF or HR in the denervated animals. This observation was used as further confirmation for completeness of the afferent denervation procedure.

All 11 animals were instrumented with electromagnetic flowmeters (Zepeda Instruments, Seattle, WA) placed around the ascending aorta and two leads anchored to the external surface of the left ventricle for direct electrocardiographic (ECG) measurement. Six animals (1 male and 5 females) served as controls and underwent all procedures except cardiac denervation. A solid-state strain gauge pressure transducer (Konigsberg Instruments, Pasadena, CA) was implanted through the apex of the left ventricle in all animals. Lead wires were exteriorized 14 days after surgery, and the presence of efferent denervation was verified pharmacologically. Water immersion studies were conducted $\sim 4$ wk postsurgery with pharmacological verification of denervation immediately after completion of the study.

Previous studies $(3,4)$ have shown that ketamine blocks the natriuretic effects of water immersion. Thus each monkey was taught to enter a restraint chair with a pole and collar system (Primate Products, Woodside, CA) and was trained over a 2 -mo period to sit quietly in a primate chair for 2 - to 4 -h periods without the use of anesthetic agents. Restraint was used with the approval of the National Aeronautics and Space Administration-Ames Research Center Institutional Animal Care and Use Committee and with the supervision of staff veterinarians. In addition to chair conditioning, the animals were trained to allow the investigator to handle arms and legs for the purpose of intravenous administration of pentobarbital anesthesia for the water immersion experiment. On the day of a study, the animals were transferred from their cages to a restraint chair and were anesthetized with pentobarbital sodium $(50 \mathrm{mg} / \mathrm{ml} ; \sim 0.5 \mathrm{ml} / \mathrm{kg}$ body wt, given to effect). Arterial and venous catheters were surgically implanted via a femoral cutdown, and a Foley catheter was inserted into the bladder via the urethra. After full instrumentation, the animal and restraint chair were placed in the empty water immersion chamber (24) for a 60-min equilibration period. This was followed by a $90-$ min control period. During this period the tank was filled with water to just below foot level and circulated by pump so as to be maintained at $34.7 \pm 0.5^{\circ} \mathrm{C}$ (Yellow Springs Instruments thermistor) by external heating coils. It took 2 min to fill the tank to the neck level with additional water during this immersion period. Water immersion was maintained for $120 \mathrm{~min}$. After immersion the tank was emptied, and a 60-min immediate recovery period was observed in which the animals were seated in the empty chamber. Blood and urine samples and cardiovascular data were obtained at 30-min intervals (i.e., 0, 30,60, and 90 min of control; $30,60,90$, and 120 min of immersion; and 30 and 60 min of recovery). Plasma from these samples was separated and stored at $-80^{\circ} \mathrm{C}$ for later analysis, and the red blood cells were rehydrated with a volume of saline equal to the volume of plasma removed. This reconstituted volume was then reinfused into the animal, and the catheters were flushed with $\sim 15-20 \mathrm{ml}$ of heparinized saline. It was estimated that the volume of saline infused averaged $150-200 \mathrm{ml}$, approximating the amount of fluid lost via blood sampling and urine production during the experiment.

Cardiovascular data were recorded continuously on an eight-channel brush recorder (Gould, Cleveland, $\mathrm{OH}$ ). $\mathrm{HR}$ and ECG were obtained via a heart rate meter (Hewlett-Packard, Waltham, MA). Peripheral arterial pressure was measured via an Ailtech pressure transducer (Electromedics, Inglewood, $\mathrm{CO}$ ), with an independent barocel electronic manometer for calibration. Left ventricular systolic and left ventricular enddiastolic pressures (LVEDP) were measured via a strain gauge pressure transducer (Konigsberg Instruments). The independently obtained peripheral arterial pressure was used to calibrate these transducers. Data reported were obtained as average values for a 50 -heartbeat segment during the last minute of each 30 -min collection period.

Urine volume was measured by completely emptying the bladder via the Foley catheter, and all volumes were collected for each 30-min period by an air wash of the bladder. Venous blood samples were collected during the last minute of each 30-min period, placed in tubes containing either EDTA or lithium heparin, and centrifuged at $4^{\circ} \mathrm{C}$. The plasma was separated and stored on ice, and the red blood cells were reinfused along with a volume of saline equal to that of the plasma removed.

Creatinine concentration was measured in plasma and urine colorimetrically with a creatinine analyzer (Beckman, Palo Alto, CA). Plasma and urine sodium and potassium concentrations were measured using ion-sensitive electrodes (model E3D, Beckman), and plasma and urine osmolalities were determined via freezing point depression osmometry (Advanced Instruments, Cambridge, MA). Values for creatinine clearance, sodium clearance, potassium clearance, free water clearance, and osmotic clearance were calculated using the urine flow rate and plasma and urine electrolyte concentrations. Fractional excretions were calculated as a percentage of creatinine clearance.

Plasma atrial natriuretic peptide (ANP) was determined using a commercially available radioimmunoassay (RIA) kit (Peninsula Laboratories, Belmont, CA). Before thawing, $50 \mu \mathrm{l}$ of aprotinin $(0.8 \mathrm{mg} / \mathrm{ml}$; Sigma Chemical, St. Louis, MO) were added to each tube of plasma. After thawing, the plasma was acidified with $1.0 \mathrm{~N} \mathrm{HCl}$ equivalent to $10 \%$ of sample volume and extracted using $\mathrm{C}_{18}$ columns (Prepsep, Fisher Scientific, Pittsburgh, PA). After adsorption, the sample was eluted using methanol and trifluoroacetic acid (90.0\% methanol-9.5\% distilled water- $0.5 \%$ trifluoroacetic acid). The eluate was dried in an evaporator/concentrator (Speed Vac, Savant Instruments, Farmingdale, NY) and then was assayed using radioimmunoassay (RIA) (30). Standards and each monkey plasma sample were run in duplicate. The extraction recovery of known quantities of ANP was $90 \%$, and the coefficient of variability within the assay was $8 \%$. Plasma renin activity (PRA) was determined using an RIA kit (New England Nuclear, Cambridge, MA) that measured the in vitro generation of angiotensin I. The within-assay coefficient of variability for the PRA assay was $8 \%$. Plasma for the measurement of plasma vasopressin (PVP) concentration was extracted using bentonite and then assayed using previously published methods (25). Standards and each monkey plasma sample were run in duplicate.

The data were analyzed with a two-way analysis of variance for repeated measures to determine differences between denervated and intact group responses. Responses within each treatment group were analyzed with one-way repeatedmeasures analysis of variance, and means were compared with control using Dunnett's test. The appropriate $t$-tests were 
Table 1. Plasma osmolality and sodium and potassium concentrations in intact and denervated monkeys

\begin{tabular}{|c|c|c|c|c|c|c|c|c|}
\hline & $\mathrm{C}-30$ & $C-60$ & C-90 & WI-30 & WI-60 & WI-120 & $\mathrm{R}-30$ & $\mathrm{R}-60$ \\
\hline \multicolumn{9}{|c|}{$\begin{array}{l}\text { Plasma osmolality, mosmol/ } \\
\qquad \mathrm{kgH}_{2} \mathrm{O}\end{array}$} \\
\hline Intact & $307 \pm 6$ & $301 \pm 3$ & $303 \pm 3$ & $306 \pm 3$ & $304 \pm 2$ & $303 \pm 2$ & $303 \pm 2$ & $301 \pm 3$ \\
\hline Denervated & $312 \pm 2$ & $314 \pm 2$ & $314 \pm 3$ & $314 \pm 3$ & $314 \pm 4$ & $314 \pm 3$ & $310 \pm 2$ & $312 \pm 3$ \\
\hline \multicolumn{9}{|c|}{ Plasma sodium, meq/I } \\
\hline Intact & $141 \pm 2$ & $142 \pm 1$ & $142 \pm 2$ & $142 \pm 2$ & $142 \pm 1$ & $141 \pm 2$ & $142 \pm 2$ & $142 \pm 2$ \\
\hline Denervated & $139 \pm 1$ & $139 \pm 1$ & $139 \pm 2$ & $139 \pm 2$ & $139 \pm 2$ & $139 \pm 2$ & $138 \pm 2$ & $138 \pm 2$ \\
\hline \multicolumn{9}{|c|}{ Plasma potassium, meq/l } \\
\hline Intact & $3.3 \pm 0.3$ & $3.3 \pm 0.2$ & $3.1 \pm 0.2$ & $3.1 \pm 0.2$ & $3.2 \pm 0.2$ & $3.1 \pm 0.2$ & $3.3 \pm 0.2$ & $3.4 \pm 0.1$ \\
\hline Denervated & $3.2 \pm 0.1$ & $3.1 \pm 0.2$ & $3.1 \pm 0.1$ & $3.1 \pm 0.1$ & $3.2 \pm 0.1$ & $3.1 \pm 0.1$ & $3.0 \pm 0.1$ & $3.0 \pm 0.1$ \\
\hline
\end{tabular}

Values are means $\pm \mathrm{SE}$ for 30,60 , and $90 \mathrm{~min}$ of control $(\mathrm{C}-30, \mathrm{C}-60$, and C-90), 120 min of head-out water immersion (WI-30, WI-60, and WI-120), and 60 min of postimmersion recovery (R-30 and R-60).

used for the separation of means. The null hypothesis was rejected when $P<0.05$.

\section{RESULTS}

Plasma data. Findings for plasma osmolality and sodium and potassium concentration (means $\pm \mathrm{SE}$ ) are given in Table 1. These variables failed to demonstrate changes with immersion in either intact or cardiacdenervated monkeys.

Renal data. Findings related to renal function are given in Figs. 1-4. After $30 \mathrm{~min}$ of immersion, urine flow increased for both groups of animals. Intact animals demonstrated $0.45 \mathrm{ml} / \mathrm{min}$ flows $(375 \%, P<0.05)$, up from preimmersion values of $0.13 \mathrm{ml} / \mathrm{min}$. Denervated animals showed increases of a similar magnitude $(P<0.05)$ from similar control levels (Fig. 1). During the next (second) 30 -min period of immersion, urine flow continued to increase to a level substantially greater than preimmersion in the intact and denervated animals. These levels were maintained over the subsequent course of immersion. After immersion, urine output returned to control levels within the first 30 min of the recovery period in both groups of animals. Urine osmotic, sodium, and potassium excretions (Fig. 2) all increased $(P<0.05)$ during water immersion and were not greater $(\boldsymbol{P}>0.05)$ for intact vs. denervated animals. Peak osmotic and sodium excretion occurred at $60 \mathrm{~min}$ of immersion for intact animals and at the end of immersion for denervated subjects (Fig. 2). Both of these parameters rapidly returned to preimmersion levels. Potassium excretion increased from $11.7 \mathrm{meq} /$ min to a peak of $30.2 \mathrm{meq} / \mathrm{min}(P<0.05)$ at $30 \mathrm{~min}$ of immersion in intact animals and gradually declined and was not statistically distinguishable from control $(17.4$ $\mathrm{meq} / \mathrm{min}, P>0.05)$ after $90 \mathrm{~min}$ of immersion. There were no differences $(P>0.05)$ between control and recovery period potassium excretion in either animal group.

Glomerular filtration rate (GFR) was estimated using endogenous creatinine clearance (Fig. 1). Compared with control, GFR increased $(P<0.05)$ in intact and denervated $(P<0.05)$ animals after $30 \mathrm{~min}$ of immersion. GFR gradually returned to preimmersion levels $(P>0.05)$ by the end of $90 \mathrm{~min}$ of immersion. Osmotic
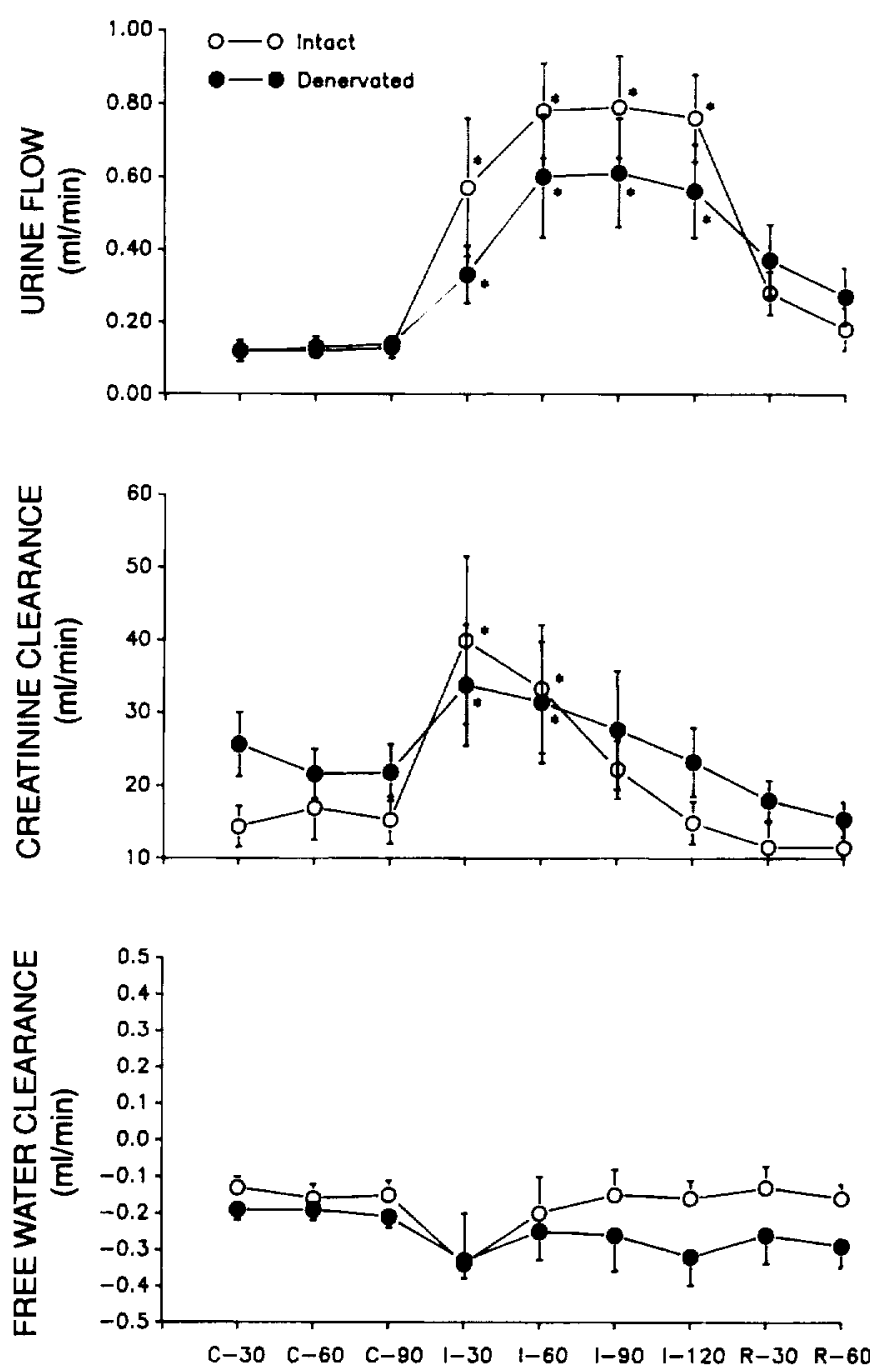

Fig. 1. Values for urine flow, endogenous creatinine clearance, and free water clearance in intact monkeys and completely cardiacdenervated monkeys (means $\pm \mathrm{SE}$ ) through $90 \mathrm{~min}$ of dry, seated control (C-30, C-60, and C-90); 120 min of head-out water immersion (I-30, I-60, I-90, and I-120); and $60 \mathrm{~min}$ of postimmersion seated recovery (R-30 and R-60). ${ }^{*}$ Significantly $(P<0.05)$ different from preimmersion. 

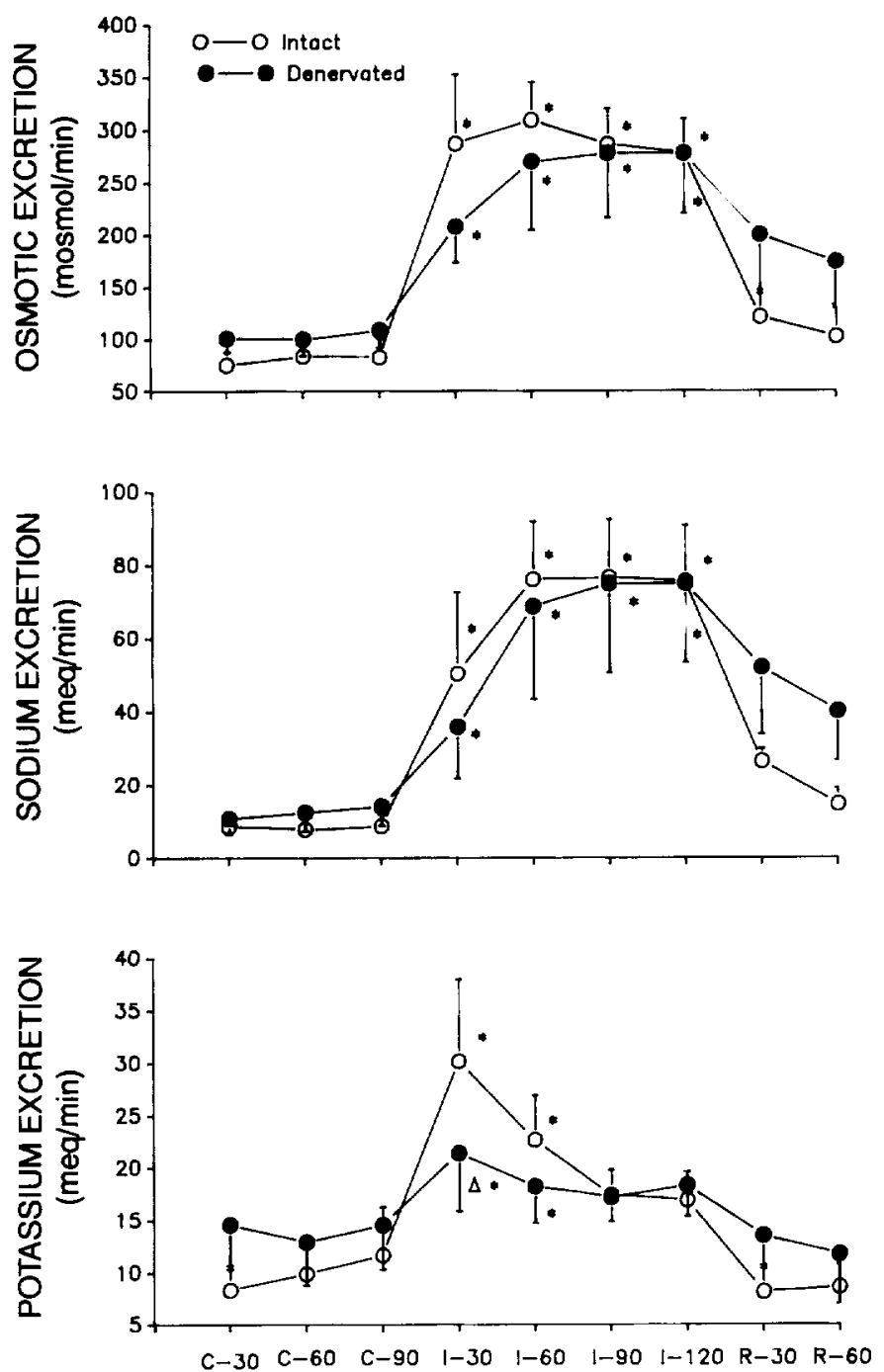

Fig. 2. Values for total urine osmotic excretion, sodium excretion, and potassium excretion in intact monkeys and completely cardiacdenervated monkeys (means $\pm \mathrm{SE}$ ) through $90 \mathrm{~min}$ of dry seated control, $120 \mathrm{~min}$ of head-out water immersion, and $60 \mathrm{~min}$ of postimmersion seated recovery, as in Fig. $1 .{ }^{*}$ Significantly $(P<0.05)$ different from preimmersion; $\Delta$, denervated monkeys significantly different $(P<0.05)$ from corresponding intact group.

clearance (Fig. 3) increased in intact $(P<0.05)$ and denervated animals $(P<0.05)$ by $60 \mathrm{~min}$ of immersion, remaining at this level until the recovery period, when mean values returned to preimmersion levels $(P>$ 0.05 ). Derived free water clearance (Fig. 1) was not altered during the experiment.

The increase in osmotic clearance was due to a marked natriuresis and kaliuresis. Sodium clearance (Fig. 3) increased in intact $(P<0.05)$ and denervated animals $(P<0.05)$ by 30 min of immersion compared with preimmersion levels. By 60 min sodium clearance peaked with an average increase of $614 \%$ in intact and denervated animals, remaining at this level for the duration of immersion. Potassium clearance increased $225 \%(P<0.05)$ in intact animals after the first $30 \mathrm{~min}$ of immersion. Peak potassium clearance in denervated animals was not reached until 60 min of immersion $(P<0.05)$ and was much lower than the peak attained by the intact animals.

Indexes of renal tubular function, such as fractional excretion of sodium (Fig. 4), increased in both groups $(87 \% ; P<0.05)$ by the first $30 \mathrm{~min}$ of immersion and peaked at $90 \mathrm{~min}$ of immersion $(300 \%, P<0.05$, in intact animals; $301 \%, P<0.05$, in denervated monkeys). Fractional excretion of potassium $\left(\mathrm{FE}_{\mathrm{K}+}\right)$ decreased $(P<0.05)$ during immersion in the denervated animals and continued to decrease during the recovery period. In contrast, intact animals showed a tendency to increase $\mathrm{FE}_{\mathrm{K}+}$ during immersion. Fractional excretion of free water increased $40 \%(P<0.05)$ in intact animals by the end of the 1 st $h$ of immersion and returned to preimmersion levels during recovery. In denervated animals, fractional excretion of free water failed to follow this pattern and decreased $(P<0.05)$ during the latter part of immersion and recovery.
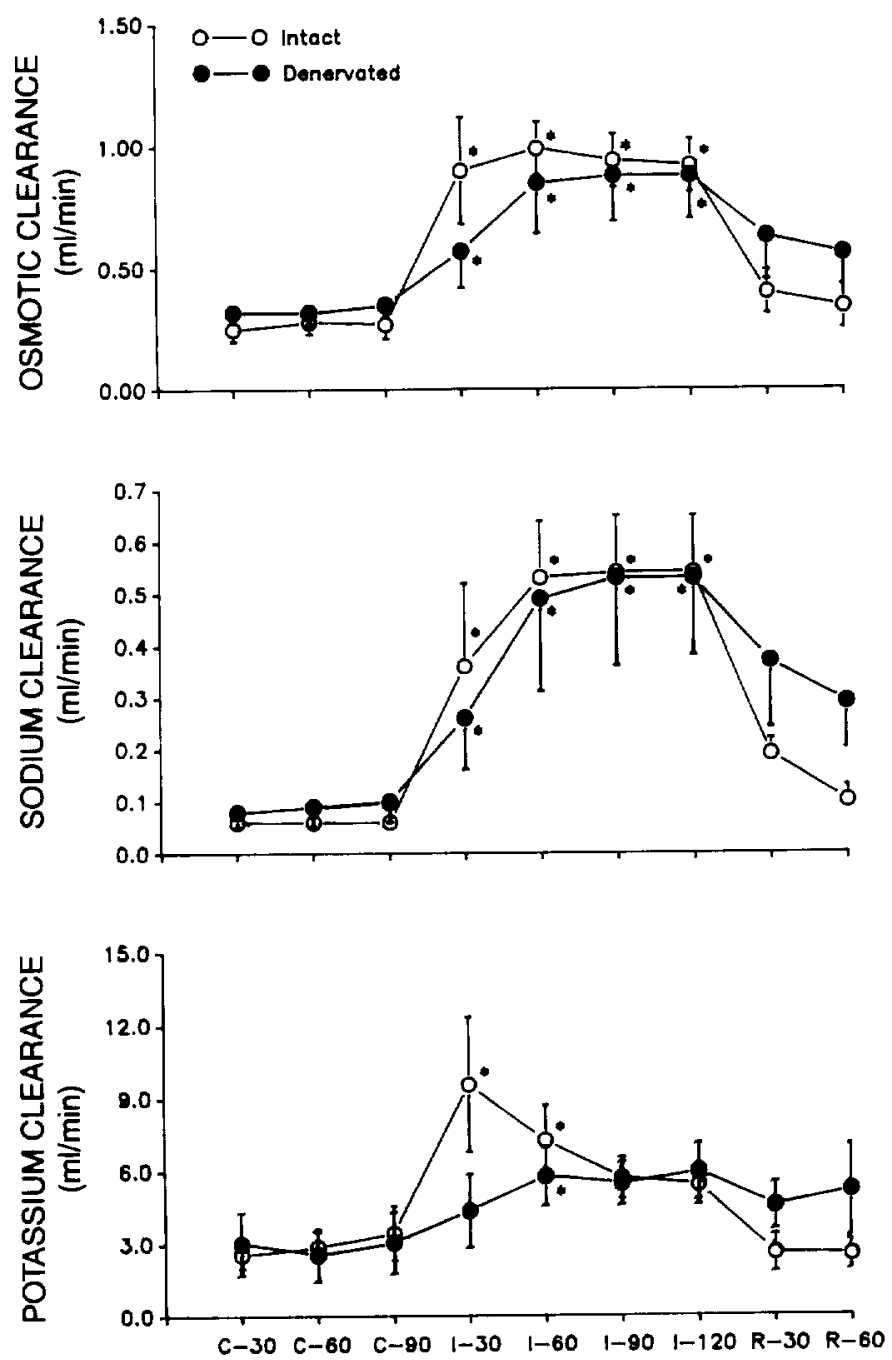

Fig. 3. Values for osmotic, sodium, and potassium clearance for intact monkeys and completely cardiac-denervated monkeys through control, immersion, and recovery periods as in Fig. 1. *Significantly different $(P<0.05)$ from preimmersion. 

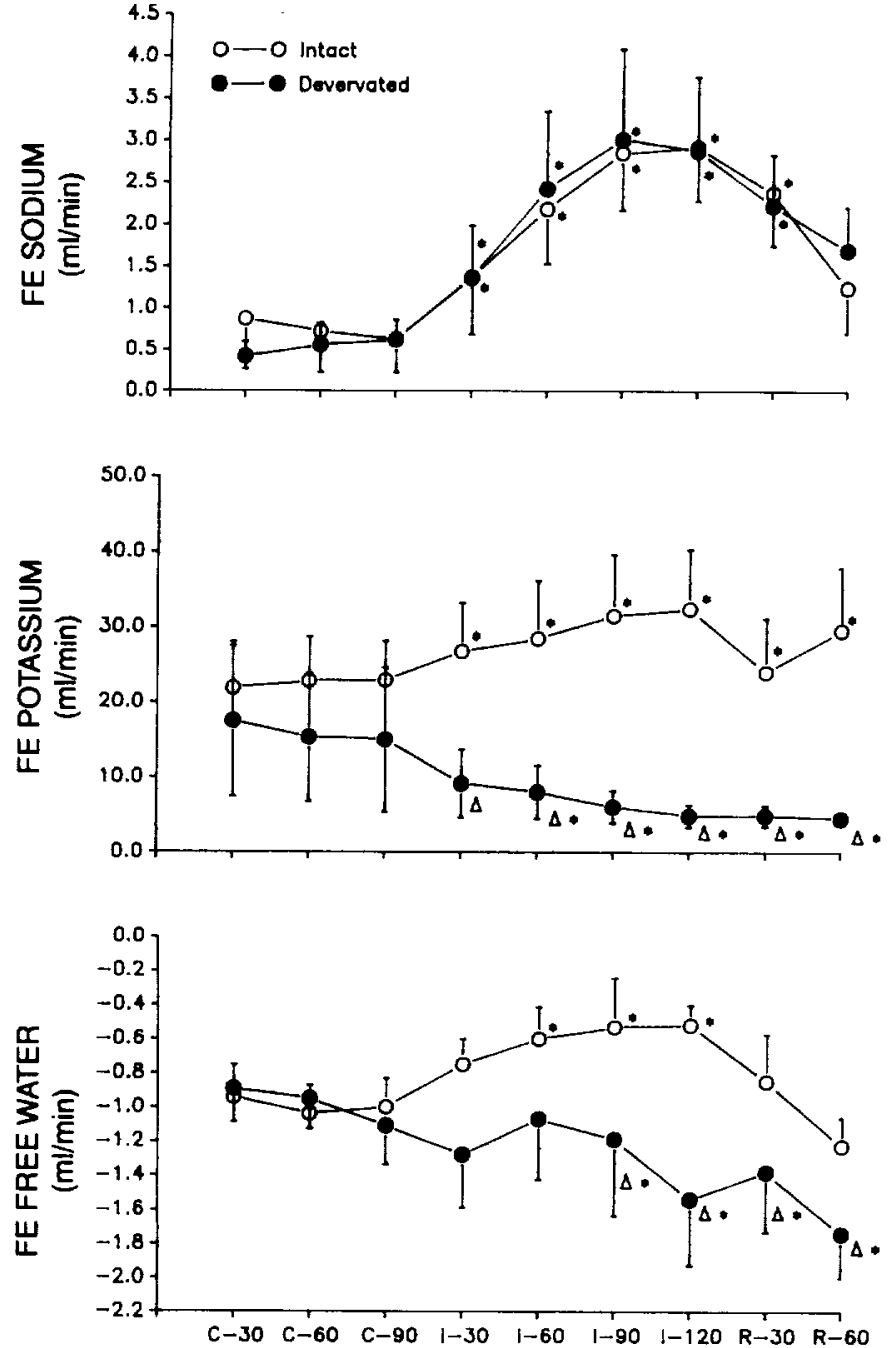

Fig. 4. Values for fractional excretion (FE) of sodium, potassium, and solute free water (means $\pm \mathrm{SE}$ ) in intact monkeys and completely cardiac-denervated monkeys through control, immersion, and recovery periods. *Significantly different $(P<0.05)$ from preimmersion; $\Delta$ significantly different $(P<0.05)$ from corresponding mean in intact group.

Endocrine data. PVP, ANP hormone concentration, and PRA data (means \pm SE) can be found in Figs. 5 and 6. PVP decreased from $39 \pm 6$ to $7 \pm 2 \mathrm{pg} / \mathrm{ml}(P<0.05)$ in the intact monkeys during water immersion and returned to baseline levels during recovery (Fig. 5). In the denervated animals PVP decreased from $53 \pm 24$ to $19 \pm 7 \mathrm{pg} / \mathrm{ml}(P<0.05)$ during the first $30 \mathrm{~min}$ of immersion but then rose and was indistinguishable from baseline levels for the remainder of the immersion period. In contrast to that in intact animals, PVP became significantly elevated $(P<0.05)$ in the denervated animals during the recovery period.

PRA was elevated $(P<0.05)$ in the denervated animals during the baseline state compared with the intact animals (Fig. 6). Values decreased for the intact group $(P<0.05)$ during immersion, reaching a nadir at 120 min of immersion. A similar trend was apparent in the denervated animals; however, this was not a significant decrease. In general, denervated animals showed

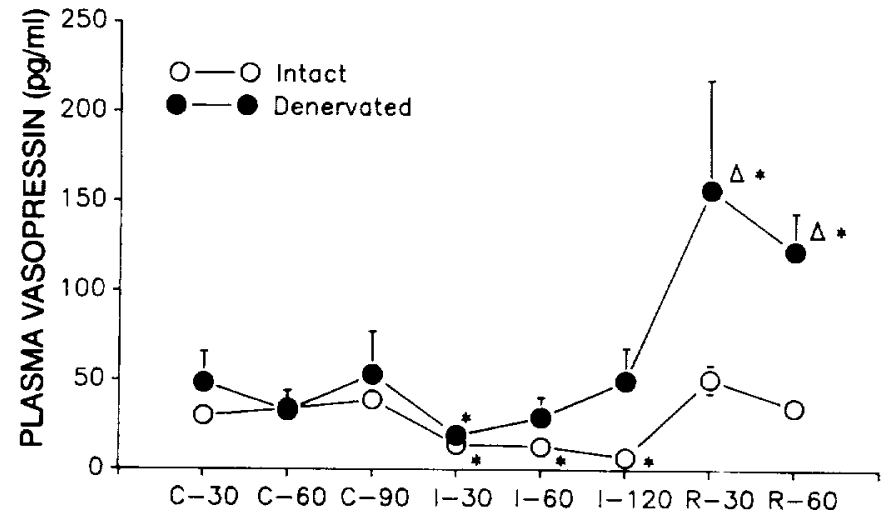

Fig. 5. Values for plasma vasopressin (PVP) for intact monkeys and denervated monkeys (means $\pm \mathrm{SE}$ ) through control, immersion, and postimmersion recovery periods. Significantly different $(P<0.05)$ from: ${ }^{*}$ preimmersion; $\triangle$, corresponding intact group.

marked variation in PRA concentrations compared with the intact animals.

Plasma ANP increased $350 \%(P<0.05)$ in intact animals and $325 \%(P<0.05)$ in denervated animals during water immersion (Fig. 6). Values returned to preimmersion levels by 60 min of recovery.

Cardiovascular data. Cardiovascular responses to water immersion (means $\pm \mathrm{SE}$ ) can be found in Figs. 7-9. Left ventricular systolic pressure (Fig. 7) was not al-
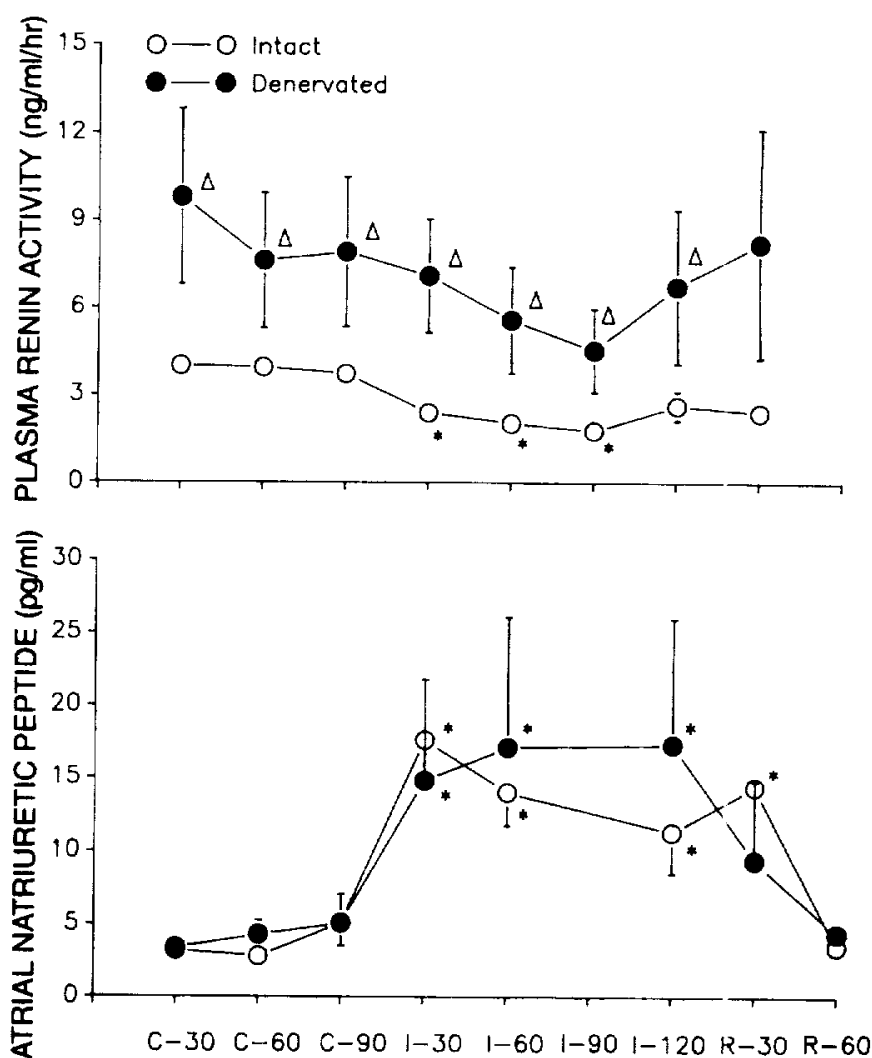

Fig. 6. Values for plasma renin activity (PRA) and plasma atrial natriuretic peptide (ANP) concentration for intact monkeys and denervated monkeys (means $\pm \mathrm{SE}$ ) through control, immersion, and postimmersion recovery periods. Significantly different $(P<0.05)$ from: * preimmersion; $\Delta$, corresponding intact group. 

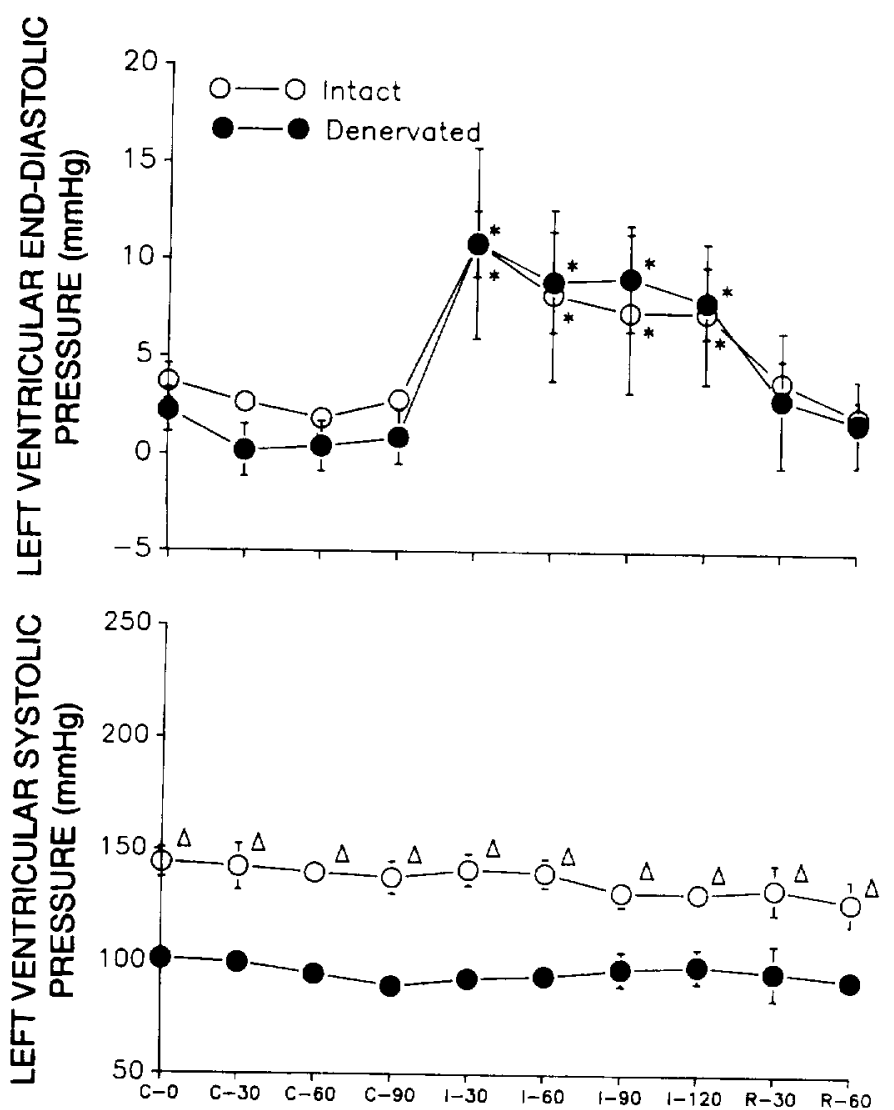

Fig. 7. Values for left ventricular end-diastolic pressure (LVEDP) and left ventricular systolic pressure for intact monkeys and denervated monkeys (means $\pm \mathrm{SE}$ ) through control, immersion, and postimmersion recovery periods. Significantly different $(P<0.05)$ from: ${ }^{*}$ preimmersion control; $\triangle$, corresponding denervated group.

tered by immersion; however, mean LVEDP (Fig. 7) increased to $10.9 \pm 4.9 \mathrm{mmHg}(P<0.05)$ in intact and to $10.9 \pm 1.7 \mathrm{mmHg}(P<0.05)$ in denervated animals at 30 min of immersion and remained at these levels for the duration of immersion. HR (Fig. 8) did not change significantly during the immersion period; however, it rose significantly in the intact animals $(P<0.05)$ compared with control during the recovery period. Cardiac output (Fig. 8) increased $\sim 11.2 \%(P<0.05)$, with a proportional $11.6 \%(P<0.05)$ increase in stroke volume in intact animals. In denervated animals, cardiac output increased $19.9 \%(P<0.05)$ through a $17.5 \%(P<0.05)$ increase in stroke volume. Mean arterial pressure (MAP, Fig. 9) was lower throughout the study in denervated animals and significantly so before immersion $(89 \pm 5$ vs. $108 \pm 5 \mathrm{mmHg}, P<0.05$ ). Mean arterial systolic, diastolic, and pulse pressures (Fig. 9) were not altered $(P>0.05)$ by immersion in either group; however, during recovery there was a $13 \%(P<0.05)$ drop in diastolic pressure and a concurrent $15 \%(P<0.05)$ drop in systolic pressure in intact animals. This resulted in a $13 \%(P<0.05)$ decrease in MAP. Mean total peripheral vascular resistance (TPR, Fig. 9$)$ was greater $(P<0.05)$ in the intact than in the denervated animals throughout the entire experiment. In the intact animals, TPR was lower than preimmersion levels $(-8 \%, P>0.05)$ after
30 min of immersion and fell farther during the recovery period to a level below preimmersion $(-15 \%, P<0.05)$. Such changes did not occur in the denervated animals.

\section{DISCUSSION}

These studies represent the first report of the renal and hemodynamic responses of cardiac-denervated nonhuman primates (Macaca mulatta) to head-out water immersion. Denervation using the Randall technique (38) failed to prevent a diuresis and natriuresis, which did not differ from the finding in similarly treated intact animals. These results indicate that triggering of low pressure located in the thorax by headward-induced fluid volume shifts and a vagal pathway (the GauerHenry reflex) may not be the responsible mechanism under these circumstances $(6,16,37,40)$. This is further supported by the work of Peterson and Jones (37), who used volume loading in identically denervated crabeating monkeys (Macaca fasicularis). They found no comparative differences in renal excretory function with
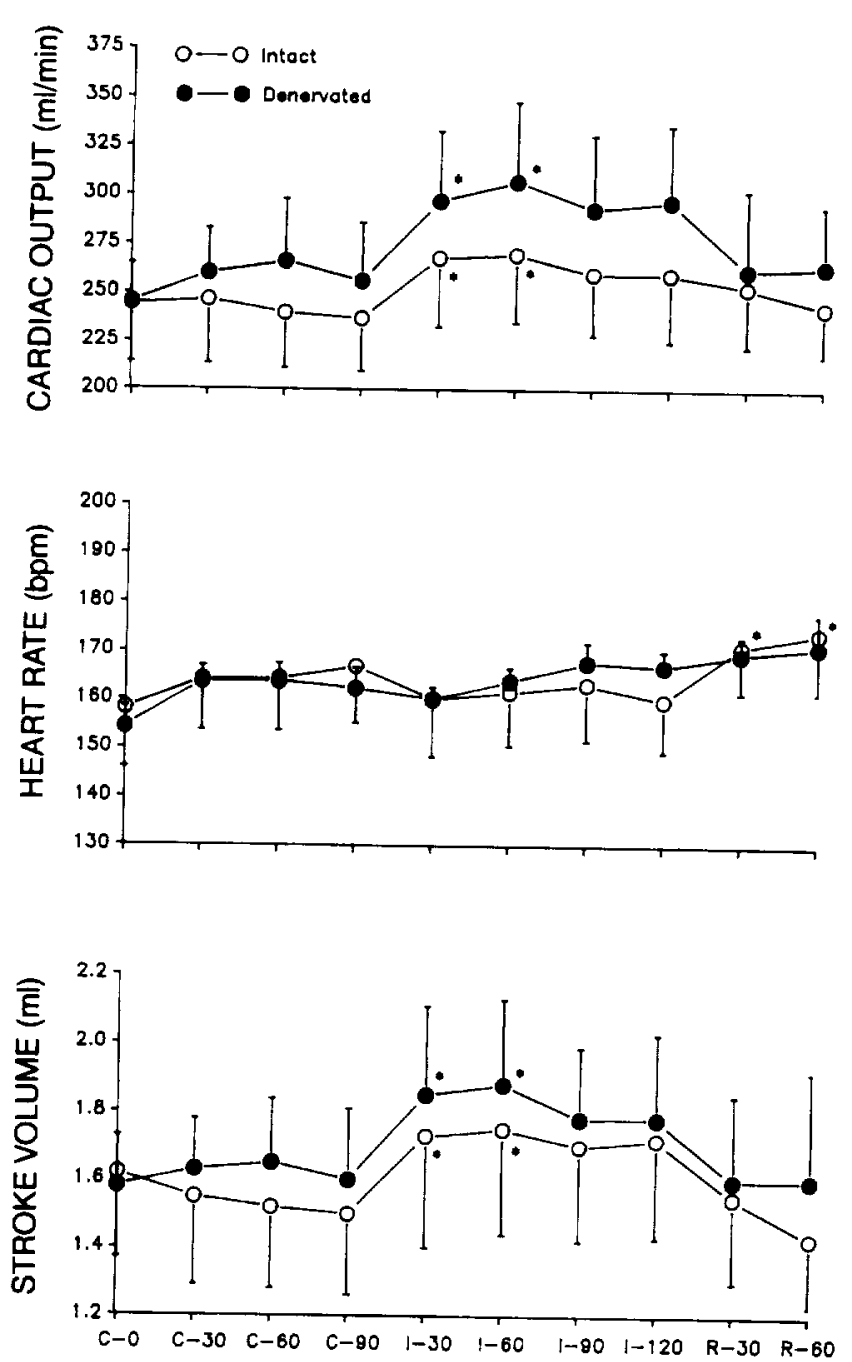

Fig. 8. Values for cardiac output, heart rate, and stroke volume for intact monkeys and denervated monkeys (means $\pm \mathrm{SE}$ ) through control, immersion, and postimmersion recovery periods. bpm, Beats $/$
min. ${ }^{*}$ Significantly different $(P<0.05)$ from preimmersion control. 

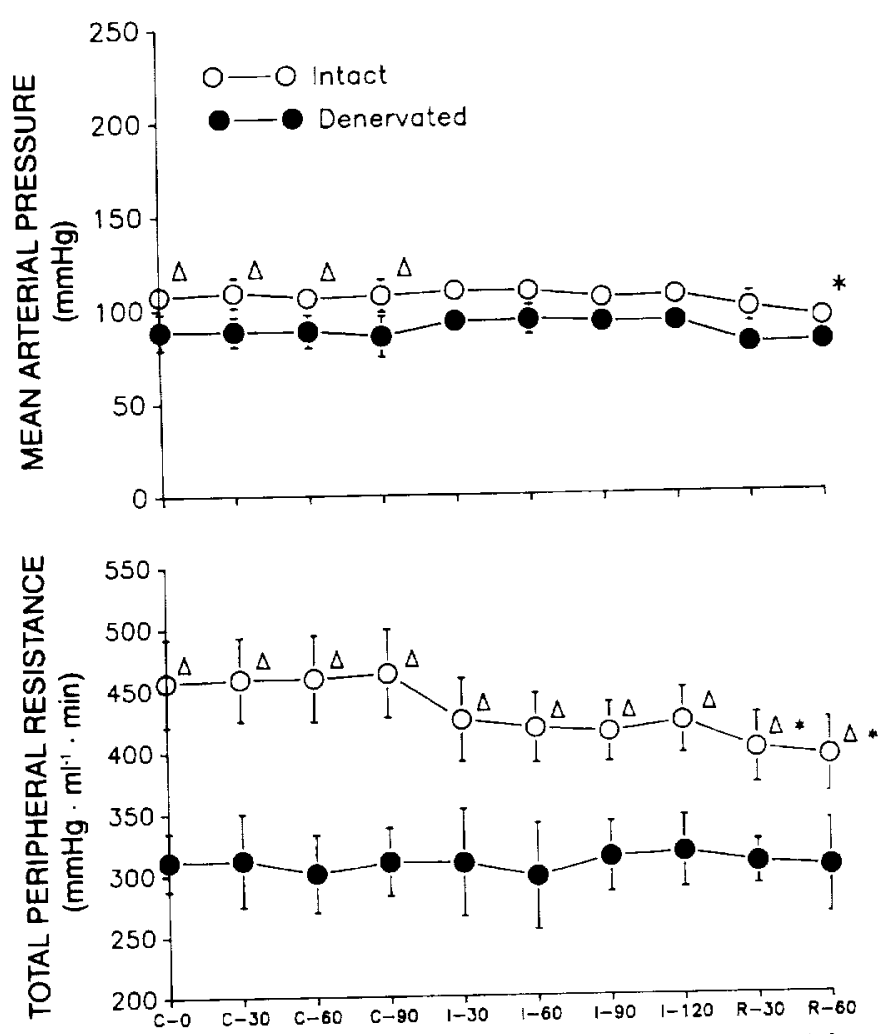

Fig. 9. Values for mean arterial pressure (MAP) and total peripheral vascular resistance (TPR) for intact monkeys and denervated monkeys (means $\pm \mathrm{SE}$ ) through control, immersion, and postimmersion recovery periods. Significantly different $(P<0.05)$ from: * preimmersion control; $\triangle$. corresponding denervated group.

sham-operated animals on intravenous central fluid loading ( $20 \%$ increase of estimated blood volume) with $6 \%$ dextran in isotonic saline infusion. Convertino et al. (6) also reported a decline in resting PVP in cardiacdenervated humans due to headward shifts induced by $6^{\circ}$ head-down tilt. Finally, these over-all data support previous studies of anesthetized rhesus and crab-eating monkeys showing that atrial stretch does not elicit a diuretic response and that vagotomy and/or dorsal root resection failed to alter an immersion-induced diuresis $(6,16,18)$. It is therefore concluded that the present studies support previous findings that the atriorenal reflex does not operate in nonhuman primates as originally described by Gauer and Henry in dogs, and that this is probably the case in humans (33).

Absolute levels for PVP in this study were quite elevated for both groups compared with values reported in ketamine-tranquilized animals or the unanesthetized state (4). These previous studies in our laboratory showed this to be specifically due to pentobarbital anesthesia (4). In four animals given $25 \mathrm{mg} / \mathrm{kg} \mathrm{Nembu-}$ tal, resting PVP was $56 \pm 11 \mathrm{pg} / \mathrm{ml}$, whereas similar levels in five tranquilized animals (ketamine $10 \mathrm{mg} / \mathrm{kg}$ ) were $14 \pm 3 \mathrm{pg} / \mathrm{m}$ and in five conscious animals were $1.8 \pm 0.9 \mathrm{pg} / \mathrm{ml}$ (3). Levels in the present study, which utilized pentobarbital anesthesia, closely match the previously reported PVP values. The dynamics of PVP changes in this study demonstrated that a decrease occurred in both groups immediately on immersion but that suppression tended to be more sustained in the intact group. More specifically, an increase in the fractional excretion of free water occurred in the intact monkeys despite the otherwise elevated PVP levels and may suggest that changes in PVP are more important than absolute resting levels, because levels recorded during immersion far exceed those seen in the normal resting state or during tranquilization. This was also the case in dogs (29). PVP levels in the present study tended to rise slightly as the immersion period progressed in the denervated group. Of note was the marked threefold PVP increase in denervated animals (compared with control) during the recovery period, whereas intact animals returned only to pretest baseline levels. This may indicate a specific role for PVP in blood pressure control in denervated animals because MAP fell in the intact animals during this period and did not do so in the denervated group $(8,9)$.

Free water clearance did not change in the present study; however, the fractional excretion of free water did increase by $40 \%$ in the intact animals. This suggests an alteration in tubular mechanisms associated with the absorption of solute free water that may have been due to the observed changes in PVP secretion. Similar changes have been reported in various animal models and humans $(35,39)$. However, the elevated levels of PVP may have been above the level needed for maximal permeability of the monkey tubule. Alternatively, the observed increase in fractional excretion of free water in the intact animals may have been influenced by the changes in other factors, such as solute load in the distal nephron, as reported by Tischer et al. (43), or the distribution of renal blood flow. Fractional excretion of free water decreased in the denervated monkeys during immersion and decreased further during recovery. Unfortunately, data from the present study cannot explain the mechanism behind this group difference.

It should be noted that a difference in MAP was present at rest and throughout the study in the two groups, MAP being lower in the denervated animals. This may have been due to lower preimmersion plasma volumes in the denervated animals. Supporting this hypothesis is the observation of lower baseline plasma volumes in human cardiac transplant patients (6). Unfortunately, plasma volumes were not measured over the course of the present study. Should resting plasma volume be lower in the denervated animals, the induced diuresis of immersion would make the denervated animal more prone to hypotension. This is further supported by observed levels of PRA in the denervated animals, which were threefold greater at rest, decreased slightly with immersion, but never reached the lower levels present in the intact animals.

Influence from high-pressure baroreceptors cannot be ruled out, but it is doubtful that they contributed in any significant way inasmuch as the same diuresis and initial suppression of PVP occurred in both groups without a change in MAP. Denervation by the Randall technique (38) does not interrupt input signals from these sensors. Continuous measurement of mean and systolic arterial pressure in the intact animals failed to 
reveal changes of note during the immersion period and failed to support previous suggestions $(2,20,28)$ that volumetric control of PVP and renin secretion are more dependent on arterial pressure changes than central venous pressure changes. Despite MAP, which was clearly lower at rest and remained so over the course of the study, denervated animals had equal magnitudes of salt and water loss compared with intact animals. A possible role for high-pressure baroreceptors in the denervated animals is supported by the work of Echtenkamp et al. (11), who showed that vagotomized monkeys still show decreases in efferent renal nerve activity with volume expansion, this response subsequently being abolished by sinoaortic denervation. The marked (threefold) PVP response postimmersion without demonstrable fall in MAP further suggests a far less important role for these mechanisms. This is further supported by changes in PVP in which both groups demonstrated a significant immediate suppression with immersion that was more prominently maintained in the intact group (Fig. 5). The reverse would have been expected should a slight but significant elevation in MAP have occurred, particularly in the denervated animals. A possible role remains for altered pulse pressure changes during immersion (34). Stroke volume (directly related to such findings) showed a tendency (but not a significant one) to be higher in the intact animals over the course of the study and more so during immersion. The tendency for PVP to increase during immersion in the denervated animals may have been related to these changes.

Vagal nerve section has been shown to decrease blood pressure in nonhuman primates and, possibly, the release of ANP (7). The lowered MAP in the present study exceeded the average 13-mmHg drop seen by Cornish et al. (7) in intact animals and approached the average $47-\mathrm{mmHg}$ drop seen in vagotomized and sinoaorticdenervated monkeys. Vagotomy in this study had no effect on baseline ANP levels. Geny et al. (15) recently reported two- to threefold increases in ANP in human cardiac transplant patients. These subjects, however, demonstrated higher MAP levels than control subjects and differ markedly in this regard from the animals in the present study. The reason remains unclear. These changes may be due to the immunosuppressive medications human subjects receive and/or the differences in renal function they may induce (32).

Plasma ANP (released from the wall of the atria by stretch) (5) had similar fourfold increases in both intact and denervated animals. Receptor sites for this hormone have been identified in many tissues, including the walls of blood vessels, hypothalamus, renal tubules, and glomerular arterioles $(5,19)$. The process of cardiac denervation would not be expected to alter stretch-induced release of such substance as evidenced by similar LVEDP between groups. Pendergast et al. (35) reported that water immersion causes a significant increase in plasma ANP and a pronounced natriuresis in humans. In the present study, an increase in GFR, an increase in the filtered load of sodium, and a decrease in sodium absorption may have been due to ANP-induced alterations in renal function. However, the role of ANP in inducing a natriuresis has recently come under question with the uncovering of urodilatin, a potent urinerecoverable hormone secreted by the kidney and acting on its distal tubules $(19,33)$. Increasing evidence in rats, dogs, and humans has shown ANP to be relatively unimportant or unnecessary for the development of a normal natriuresis with oral salt loading or infusion (19). Its most likely role appears to be in cardiovascular regulation, where ANP can cause a vasodilatation of selected vascular beds in the peripheral vasculature (5, 19). Finally, it has been shown that ANP has an inhibitory effect on release of PVP from the hypothalamus (5). The rise in ANP in the denervated monkeys may have contributed to the suppression of PVP during the first 30 min of immersion. A rise in PVP occurred in the recovery period in both groups, associated with a fall in ANP. Urodilatin was not measured during these studies.

In the present study GFR, as measured by creatinine clearance, increased during the $1 \mathrm{st} h$ of immersion and returned to preimmersion levels by $90 \mathrm{~min}$. Potassium excretion paralleled potassium clearance without an increase in fractional potassium excretion, suggesting that the increased loss of potassium was due to a GFR-induced change in the filtered load of potassium and not a change in tubular absorption or secretion. Thus it would appear that water immersion caused a kaliuresis that contributed to the early phase of increase in urine losses. Interestingly, sodium excretion and clearance both rose during the first $30 \mathrm{~min}$ of immersion and both peaked at $60 \mathrm{~min}$. Fractional excretion of sodium did not increase until $60 \mathrm{~min}$. Therefore it would appear that the natriuresis was facilitated by a twophase mechanism in both study groups. During the first phase, starting within the first $30 \mathrm{~min}$ of immersion, losses were the result of a change in GFR and filtered sodium load. By $90 \mathrm{~min}$ of immersion a second phase was initiated, with the return of GFR to normal levels and a delayed increase in fractional excretion. This phase was associated with factors affecting tubular sodium absorption and was not dependent on an increased sodium load. Similar changes in GFR and fractional sodium excretion have been reported in humans during water immersion (35). Still, the state of fluid hydration (slight dehydration) in both animal groups cannot be ruled out as a contributor to these findings (34). Although plasma volume, red blood cells, and lost urine volumes were replaced by periodic saline infusion, the animals may have become slightly dehydrated as the study progressed because of errors in intake-output measurement and fluid loss through the skin when immersed.

Hemodynamic measurements indicated an identical threefold rise in left ventricular filling pressure in both groups, without change in HR, consistent with findings previously reported of a marked increase in central venous pressure and lack of a Bainbridge reflex response in nonhuman primates and humans (16). On immersion, denervated animals showed no change in their after load but tended to have greater stroke volume and 
ensuing cardiac output, suggesting they were more sensitive to resultant Starling effects.

In the present study, we observed a decrease in TPR in the intact animals during immersion. The observed decrease in PRA may partially explain why TPR tended to fall in the intact animals. In contrast, neither TPR nor PRA decreased in the denervated animals during immersion. The reason for these latter observations remains unexplained, and future studies are needed to determine the mechanisms mediating these responses.

\section{Perspectives}

The exact mechanisms responsible for immersioninduced PVP suppression in this study are unknown. A diuresis occurred despite atrial distension (elevated LVEDP) and absence of a vagal afferent limb. This may indicate that an induced increase in central venous pressure may still be an important triggering mechanism, operating, however, through input from an elevation in cerebrospinal fluid pressure (CSFP) rather than from altered nervous system traffic. Because right heart pressure has direct communication to the cerebrospinal fluid in all mammalian species (including dog, nonhuman primate, and human), a headward fluid shift during immersion must result in some elevation in CSFP (24) and could result in PVP suppression. This is supported by recent work in nonhuman primates (24) showing that immersion increases CSFP and that PVP secretion in rats can be inhibited through elevation of CSFP (41, 42 . This hypothesis would explain findings reported by Gilmore and co-workers (16-18) of a diuresis with immersion or volume loading in nonhuman primates despite vagotomy, sinoaortic resection, dorsal rhizotomy, and cardiac denervation. It would not explain the absence of immersion response with vagotomy in dogs, which also have direct right-sided pressure communication with cerebrospinal fluid $(13,14)$. This may instead indicate, as previously reported, that dogs have greater sensitivity to thoracically located low-pressure mechanoreceptors compared with nonhuman primates. However, in some experiments an immersion-induced diuresis has occurred in dogs despite vagotomy (10).

In all the above experiments the focus has been on a change in left atrial transmural pressure, rather than right heart pressure, which has not been reported under these circumstances. An increased left heart pressure is not sufficient evidence to assume its transmission to the right side through the highly compliant pulmonary vascular bed. This may also explain findings of a lack of renal response to acute elevations of left atrial pressure by snaring in monkeys by Gilmore (16), these animals later responding to acute volume loading with use of dextran.

Finally, a recent report by Rossi (39) has implicated factors that affect endothelin-3 levels in the release of PVP and actions in vivo in rats. Unfortunately, most previously reported data on fluid volume control in the nonhuman primate have centered on renal nerve influences and have not included measurements of PVP. Further water immersion studies are clearly needed in which CSFP is directly measured and/or independently manipulated to induce changes in salt and water excretion and which include measurement of PVP and other important substances, such as urodilatin and endothelin.

The authors express their appreciation to Vera Shavlach and Tom Dickey for surgically preparing the animals used in this study; Jerry Hart and Steven Tebb for assistance in collection of data and care of the animals; John Hines and Mike Skidmore for providing engineering support; John Cummings for assistance in the setup and maintenance of the electronic equipment; and Jodi Cooley for help with the ANP assays.

The majority of work was done while $\mathrm{K}$. H. McKeever was a National Academy of Sciences-National Research Council-National Aeronautics and Space Administration Resident Research Associate. A portion of this work was performed while he was the recipient of the American Heart Association (Central Ohio Affiliate) Young Investigator Award.

Address for reprint requests: K. H. McKeever, Dept. of Animal Sciences, Cook College, Rutgers, The State Univ. of New Jersey, New Brunswick, NJ 08903.

Received 7 September 1993; accepted in final form 3 November 1994.

\section{REFERENCES}

1. Arborelius, M., U. I. Balldin, B. Lilja, and C. E. G. Lundgren. Hemodynamic changes in man during immersion with the head above water. Aerospace Med. 43: 592-598, 1972.

2. Arnauld, E., P. Czernichow, F. Fumoux, J. Vincent. The effects of hypotension and hypovolemia on the liberation of vasopressin during hemorrhage in the unanesthetized monkey (Macaca mulatta). Pfluegers Arch. 371: 193-200, 1977

3. Benjamin, B. A., L. C. Keil, M. S. Shapiro, M. A. Kirschenbaum, N. S. Bricker, and H. Sandler. Physiologic response to water immersion in the rhesus monkey (Abstract). Federation Proc. 26: A11, 1983.

4. Benjamin, B. A., M. S. Shapiro, N. S. Bricker, and H. Sandler. Water immersion in the conscious monkey (Abstract). Physiologist 25: 196, 1982.

5. Brenner, B. M., B. J. Ballermann, M. E. Gunning, and M. L. Zeidel. Diverse biological actions of atrial natriuretic peptide. Physiol Rev. 70: 665-699, 1990.

6. Convertino, V. A., C. A. Thompson, B. A. Benjamin, L. C. Keil, w. M. Savin, E. P. Gordon, W. L. Hasdell, J. S. Schroeder, and H. Sandler. Haemodynamic and ADH responses to central blood volume shifts in cardiac-denervated humans. Clin. Physiol. Oxf. 10: 55-67, 1990.

7. Cornish, K. G., M. Barazanji, A. Ryberg, and J. P. Gilmore. Hypotension produced by vagal block in primates. Am. J. Physiol. 254 (Regulatory Integrative Comp. Physiol. 23): R857-R862, 1988.

8. Cowley, A. W., and J. F. Liard. Vasopresssin and arterial pressure regulation. Hypertension Dallas 11, Suppl. 1: I25-132, 1988.

9. Cowley, A. W., E. Monou, and A. C. Guyton. Interaction of vasopressin and the baroreceptor reflex system in the regulation of arterial blood pressure in the dog. Circ. Res. 34: 505-514, 1974.

10. Davis, J. T., and A. B. DuBois. Immersion diuresis in dogs. $J$. Appl. Physiol. 42: 915-922, 1977.

11. Echtenkamp, S. F., I. H. Zucker, J. P. Gilmore. Characterization of high and low pressure baroreceptor influences on renal nerve activity in the primate Macaca fascicularis. Circ. Res. 46: $726-730,1980$.

12. Epstein, M., D. S. Pins, and M. Miller. Suppression of $\mathrm{ADH}$ during water immersion in normal man. J. Appl. Physiol. 38: $1038-1044,1975$

13. Gauer, O. H. Body fluid regulation during immersion. In: Hypogravic and Hypodynamic Environments, edited by R. $\mathrm{H}$. Murray and N. McCally. Washington, DC: NASA, 1971, p. 345357. (pub. no. SP-269)

14. Gauer, O. H., J. P. Henry, and C. Behn. The regulation of extracellular fluid volume. Annu. Rev. Physiol. 32: 547-595, 1970. 
15. Geny, B., F. Piquard, M. Follenius, B. Mettauer, A. Schaeffer, B. Canguilhem, B. Eisenmann, and P. Haberey. Role of cardiac innervation in atrial natriuretic peptide secretion in transplanted heart recipients. Am. J. Physiol. 265 (Renal Fluid Electrolyte Physiol. 34): F112-F118, 1993.

16. Gilmore, J. P. Neural control of extracellular volume in the human and non-human primate. In: Handbook of Physiology. The Cardiovascular System. Peripheral Circulation and Organ Blood Flow. Bethesda, MD: Am. Physiol. Soc., 1983, sect. 2, vol. III, pt. 2, chapt. 24, p. 885-915.

17. Gilmore, J. P., T. V. Peterson, and I. H. Zucker. Neither dorsal root nor baroreceptor afferents are necessary for eliciting the renal response to acute volume expansion in the primate Macaca fascicularis. Circ. Res. 45: 95-99, 1979

18. Gilmore, J. P., and I. H. Zucker. Contribution of vagal pathways to the renal responses to head-out immersion in the non-human primate. Circ. Res. 42: 263-267, 1978.

19. Goetz, K. L. Renal natriuretic peptide (urodilatin?) and atriopeptin: evolving concepts. Am. J. Physiol. 261 (Renal Fluid Electrolyte Physiol. 30): F921-F932, 1991.

20. Goldsmith, S. R., A. W. Cowley, G. S. Francis, and J. N. Cohn. Effect of increased intracardiac and arterial pressure on plasma vasopressin in humans. Am. J. Physiol. 246 (Heart Circ. Physiol. 15): H647-H651, 1984.

21. Greenleaf, J. E., J. T. Morse, P. R. Barnes, J. Silver, and L. C. Keil. Hypervolemia and plasma vasopressin response during water immersion in men. J. Appl. Physiol. 55: 1688-1693, 1983.

22. Greenleaf, J. E., E. Shvartz, and L. C. Keil. Hemodilution, vasopressin suppression and diuresis during water immersion in man. Aviat. Space Environ. Med. 52: 329-336, 1981.

23. Hajduczok, G., K. Miki, S. K. Hong, J. R. Claybaugh, and J. A. Krasney. Role of cardiac nerves in response to head-out water immersion in conscious dogs. Am. J. Physiol. 253 (Regulatory Integrative Comp. Physiol. 22): R242-R253, 1987.

24. Keil, L. C., K. H. McKeever, M. G. Skidmore, J. Hines, and W. B. Severs. The effect of head-down tilt and water immersion on intracranial pressure in nonhuman primates. Aviat. Space Environ. Med. 63: 181-185, 1992.

25. Keil, L. C., and W. B. Severs. Reduction in plasma vasopressin levels of dehydrated rats following acute stress. Endocrinology 100: $30-38,1977$

26. Krasney, J. A., M. Carroll, E. Krasney, J. Iwamoto, J. R. Claybaugh, and S. K. Hong. Renal, hormonal, and fluid shift responses to ANP during head-out water immersion in awake dogs. Am. J. Physiol. 261 (Regulatory Integrative Comp. Physiol. 30): R188-R197, 1991

27. Kravik, S. E., L. C. Keil, J. E. Silver, N. Wong, w. A. Spaul, and J. E. Greenleaf. Immersion diuresis without expected suppression of vasopressin. J. Appl. Physiol. 57: 123-128, 1984.

28. Mark, A. L., F. M. Abboud, A. E. Fitz. Influence of low- and high-pressure baroreceptors on plasma renin activity in humans. Am. J. Physiol. 235 (Heart Circ. Physiol. 4): H29-H33, 1978.
29. Mason, J. M., and J. R. Ledsome. The effect of changes in rate of infusion of vasopressin in the anesthetized dog. Can. J. Physiol. Pharmacol, 49: 933-940, 1971.

30. McKeever, K. H., K. W. Hinchcliff, L. M. Schmall, and W. W. Muir III. Renal tubular function in horses during submaximal exercise. Am. J. Physiol. 261 (Regulatory Integrative Comp. Physiol. 30): R553-R560, 1991

31. McKeever, K. H., M. G. Skidmore, L. C. Keil, and $H$. Sandler. Intrapericardial denervation: radial artery blood flow and heart rate responses to LBNP. J. Appl. Physiol. 68: 22082213,1990

32. Myers, B. D., C. Peterson, C. Molina, S. J. Tomlanovich, L. D. Newton, R. Nikitin, H. Sandler, and F. Murad. Role of the cardiac atria in the human response to changing volume. Am. J. Physiol. 254 (Renal Fluid Electrolyte Physiol. 23): F562F573, 1988

33. Norsk, P., C. Drummer, L. B. Johansen, and R. Gerzer. Effect of water immersion on renal natriuretic peptide (urodilatin) excretion in humans. J. Appl. Physol. 74: 2881-2885, 1993.

34. Norsk, P., and M. Epstein. Effects of water immersion on arginine vasopressin release in humans. J. Appl. Physiol. 64 $1-10,1988$.

35. Pendergast, D. R., A. J. De Bold, M. Pazik, and S. K. Hong. Effect of head-out immersion on plasma atrial natriuretic factor in man. Proc. Soc. Exp. Biol. Med. 184: 429-435, 1987.

36. Peterson, T. V., B. A. Benjamin, and N. L. Hurst. Effect of vagotomy and thoracic sympathectomy on responses of the monkey to water immersion. J. Appl. Physiol. 63: 2476-2481, 1987.

37. Peterson, T. V., and C. E. Jones. Renal responses of the cardiac-denervated nonhuman primate to blood volume expansion. Circ. Res. 53:24-32, 1983

38. Randall, W. C., M. P. Kaye, J. X. Thomas, and M. J. Barber. Intrapericardial denervation of the heart. J. Surg. Res. 29: 101-109, 1980

39. Rossi, N. F. Effect of endothelin-3 on vasopressin release in vitro and water excretion in vivo in Long-Evans rats. J. Physiol. Lond. 461: 501-511, 1993

40. Sandler, H. Cardiovascular effects of inactivity. In: Inactivity: Physiological Effects, edited by H. Sandler and J. Vernikos. Orlando, FL: Academic, 1986, chapt. 2, p. 11-47.

41. Severs, W. B., R. D. Hartman, B. A. Morrow, and L. C. Keil. Cerebrospinal fluid pressure of conscious rats after venous constriction at the right atrium. Pharmacology Basel 43: 151-155, 1991.

42. Severs, W. B., L. C. Keil, J. N. D. Wurpel, and R. L. Dundore. Cerebrospinal fluid pressure of conscious rats: effects of artificial CSF, angiotensin, and vasopressin. In: Brain Peptides and Catecholamines in Cardiovascular Regulation, edited by J. P. Buckley and C. M. Ferrario. New York: Raven, 1987, p. 403-415.

43. Tischer, C. C., R. W. Schrier, and J. S. McNeal. Nature of urine concentrating mechanism in the macaque monkey. $A m$. J. Physiol. 223: 1128-1137, 1972. 


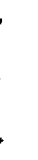

